\title{
Transcervical embryo recovery in Saanen goats
}

\author{
J.B. Lima-Verde, E.S. Lopes Júnior, D.I.A. Teixeira, N.R.O. Paula, A.A. Medeiros, \\ D. Rondina and V.J.F. Freitas \\ Laboratory of Physiology and Control of Reproduction, State University of Ceará - Faculty of Veterinary Science \\ Fortaleza - CE, 60.740-000, Brazil
}

\begin{abstract}
In order to study the embryo recovery rate using the transcervical technique in Saanen goats raised in the tropics, 20 donors were submitted to an oestrus synchronisation treatment using intravaginal progestagen sponges for 11 days. On the ninth day of treatment, goats received intramuscular injections of $50 \mu \mathrm{g}$ cloprostenol and six injections of porcine follicle stimulating hormone (pFSH) at 12-hour intervals. Does in oestrus were mated by Saanen bucks. Donors received an intramuscular injection of $50 \mu \mathrm{g}$ cloprostenol 24 hours before embryo collection. At this time, the ovaries were observed by laparoscopy to verify the ovulation rate. The embryo recovery was performed six to seven days after oestrus onset by transcervical technique. Goats in which the cervix was not penetrable were submitted to embryo recovery by laparotomy. The recovered embryos were classified according to the International Embryo Transfer Society (IETS) guidelines. Oestrus was observed in $85 \%$ of goats. A response to superovulatory treatment was observed in $65 \%$ of goats and a mean ovulation rate of $11.5 \pm 6.6$ was recorded. The cervix was penetrable in $61.5 \%$ of goats. In the remaining goats the embryo recovery was performed by laparotomy. The recovery rate was $53.2 \%$ and $36.9 \%$ using transcervical and surgical methods, respectively. Quanti-qualitative embryo production was similar in both techniques. Embryo recovery by the transcervical technique was shown to be an alternative for collection of embryos in Saanen goats. However, further studies should be done in order to improve both the cervix penetrability and embryo recovery rate.
\end{abstract}

Keywords: Goats, embryo recovery, transcervical technique, Saanen, tropics, superovulation

"Corresponding author. E-mail address: vjff@uece.br

\section{Introduction}

The goat population in the northeast of Brazil represents about $94 \%$ of the total population in the country (IBGE, 1998). However, despite their prominence, the national flock exhibits a low productivity. It consists, in general, of animals of undefined breed, with a high rusticity, but low milk production. Therefore, in order to improve the productivity, the importation of animals of specialised breeds became necessary. Among these, the Saanen breed is particularly important, because it is well adapted to environment conditions such as high ambient temperatures and seasonal variations in forage supply, and represents a very suitable model for implementing dairy goat production systems.

In order to multiply the characteristics of genetically superior animals, embryo transfer technology has been used to provide a more rapid increase in the genetic quality of livestock populations. However, it was not until embryo transfer developed as an industry in cattle breeding in the mid-1970s that similar technologies were adopted in goat breeding. Since then, embryos from thousands of goats have been collected and transferred. Three countries, Australia, New Zealand and South Africa, are particularly prominent in this field of activity (Thibier \& Guérin, 2000).

For the success of embryo transfer, the control of certain stages is essential, including embryo recovery. Among the methods used for embryo recovery in goats, laparotomy is utilised most frequently (Tervit et al., 1983; Kraemer, 1989). The occurrence of post-surgical adhesions has prompted the development of embryo recovery by laparoscopy (Baril et al., 1989; Vallet et al., 1991; Flores-Foxworth et al., 1992) and, more recently, by transcervical recovery (Pereira et al., 1998). This last technique aims at minimising the trauma to the doe, and making it possible to recover a greater number of embryos per donor. However, this technique is not widely used due to the difficulty of passing through the cervix of a doe with the devices used for embryo recovery. Trials have been conducted to facilitate this process, especially in the Boer goats (Pereira et al., 1998; Suyadi et al., 2000). However, attempts to use transcervical techniques in the Saanen breed are minimal (Pereira et al., 1991). Therefore, the objective of the present study was to verify the embryo recovery rate, using a transcervical technique in Saanen goats raised under tropical conditions. 


\section{Materials and Methods}

The experiment was conducted at the Laboratory of Physiology and Control of Reproduction, located in Fortaleza, Brazil at $3^{\circ} 43^{\prime} 47^{\prime \prime}$ South and 38 30'37' 'West. Twenty Saanen goats aged $3.3 \pm 2.2$ years and weighing $40.5 \pm 9.1 \mathrm{~kg}$ served as embryo donors. Animals were housed indoors and fed elephant grass (Pennisetum purpureum) and a commercial grain supplement (18.0\% crude protein). Water and a mineral salt lick were provided ad libitum. The treatment for oestrus synchronisation was performed using intravaginal progestagen sponges with $60 \mathrm{mg}$ of acetate medroxiprogesterone (Promone E, Rhodia-Mérieux, Brazil) for 11 days. On the ninth day of the progestagen treatment, an intramuscular injection of $50 \mu \mathrm{g}$ cloprostenol (Ciosin, Coopers, Brazil) was administered. During days 9, 10 and 11 of the progestagen treatment donor does were subjected to superovulation using $200 \mathrm{mg}$ porcine follicle stimulating hormone (pFSH) (Folltropin V, Vetrepharm, Canada) administered intramuscularly at 12 hour intervals in decreasing doses (40 mg/40 mg; $40 \mathrm{mg} / 40 \mathrm{mg} ; 20 \mathrm{mg} / 20 \mathrm{mg}$ ). Vaginal sponges were removed at the time of the fifth pFSH dose.

Females were tested for oestrus with the aid of two fertile males from 12 hours after sponge removal every four hours for as long as they exhibited standing oestrus. Goats were mated only at the onset of oestrus and 24 hours after the initial detection of oestrus. Twenty four hours prior to embryo recovery the goats were treated with an intramuscular injection of $50 \mu \mathrm{g}$ cloprostenol. At this time a laparoscopy was performed according to the technique described by Oldham \& Lindsay (1980) to determine the ovulation rate and to serve as an indicator of the maximum number of estimated embryos. Those goats with five or more corpora lutea (CL) were considered to have been responsive to the superovulatory treatment. The transcervical embryo recovery in the superovulated goats was performed six to seven days after onset of oestrus. These goats initially received $3.3 \mathrm{mg} \mathrm{2.0 \%}$ lidocaine cloridrate (Anesthetic L, Pearson, Brazil) by the epidural route. A speculum was introduced into the vagina and the external lip of the cervix was grasped and carefully pulled caudally with the aid of two no. 20 Allis forceps. With the aid of a guide, a flushing catheter (nasogastric probe 10, Embramed, Brazil) was introduced through the cervix until it reached the uterus. After removing the guide $20 \mathrm{~mL}$ of flushing medium (DPBS) at $37^{\circ} \mathrm{C}$ was infused into the uterus. This process was repeated 25 times. Each infusion of $20 \mathrm{~mL}$ of medium uterus effluent was recovered in a millipore filter $(0.22 \mu \mathrm{m})$. In the females where the catheter could not be passed transcervically the embryo recovery was performed by laparotomy according to method described by Baril et al. (1995). The recovered effluent in both techniques was inspected under a stereomicroscope (Nikon, Japan) at a magnification of 40-70x to identify and evaluate structures. Embryos were classified into categories: I (excellent), II (fair), III (poor), IV (dead/degenerated) or unfertilised, in accordance with the guidelines of the International Embryo Transfer Society (IETS).

The recovery rate was calculated as the number of oocytes or embryos recovered/number of CL counted. The values obtained, were expressed as mean \pm s.d. or as percentages. The values were compared by the Chi Square test. Data of recovered embryos were transformed to a log function and the means were compared by ANOVA followed by the Fischer test. All statistical analyses were performed using the software StatView 5.0 (SAS, 1995).

\section{Results}

Oestrus was observed in $85 \%(17 / 20)$ of the treated does. The interval recorded between sponge removal and onset of oestrus was $19.8 \pm 9.7$ hours (Figure 1) and the mean length of oestrus was $40.5 \pm 10.9$ hours. A superovulatory response to treatment was observed in $65 \%(13 / 20)$ of the females and the overall ovulation rate recorded was $11.5 \pm 6 \mathrm{CL}$ per goat. Cases of early regression of CL were not observed.

At the embryo recovery attempt, the cervix was passable in $61.5 \%(8 / 13)$ of the goats. For this method, the recovery rate was $53.2 \%$. In the goats where the catheter could not be passed through the cervix (5/13), embryo recovery was performed by laparotomy, with a recovery rate of $36.9 \%$. No significant difference was observed between the embryo recovery methods (transcervical vs. laparotomy; $\mathrm{P}>0.05$ ).

The quanti-qualitative production of embryos obtained by the two different embryo recovery techniques showed no significant difference for any of the parameters studied: number of CL and recovered embryos as well as the quality of embryos (Table 1). 


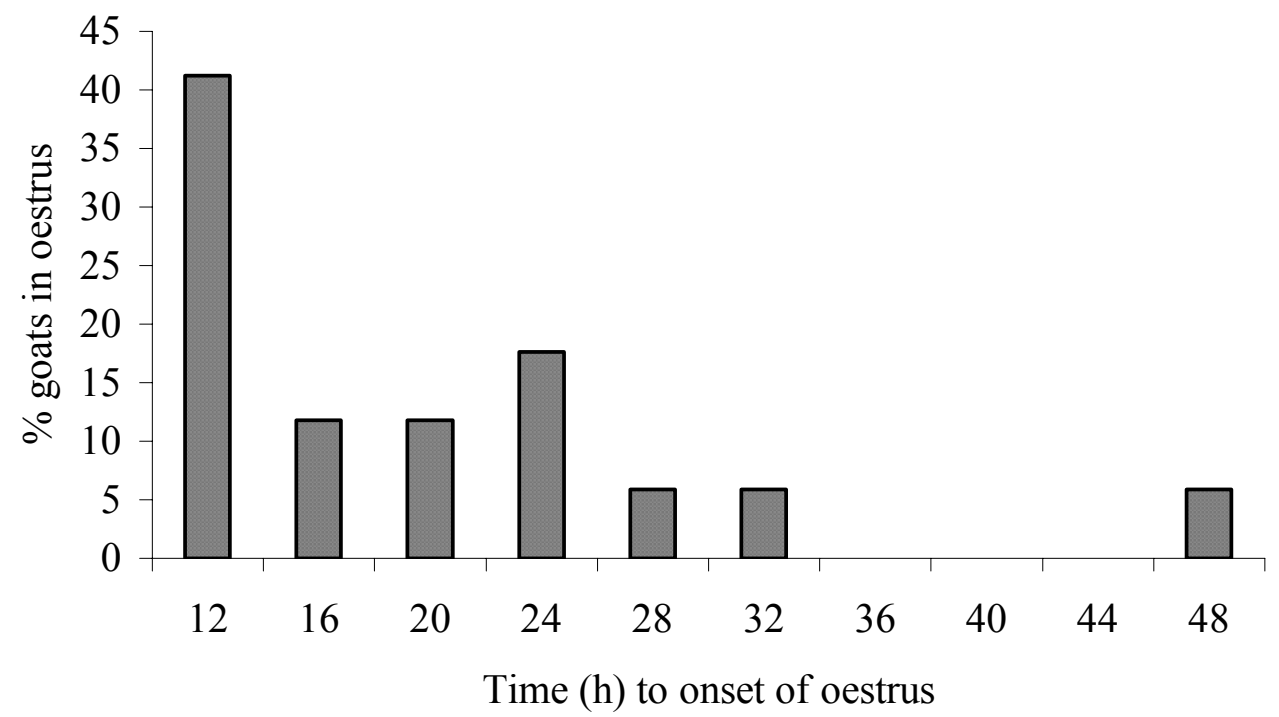

Figure 1 Distribution of the onset of oestrus after superovulation treatment in Saanen goats

Table 1 Response of Saanen goats to superovulation and embryo recovery by transcervical or laparotomy techniques

\begin{tabular}{|c|c|c|c|c|c|c|c|c|c|c|}
\hline \multirow{2}{*}{$\begin{array}{l}\text { Recovery } \\
\text { Technique }\end{array}$} & \multirow[b]{2}{*}{$\mathbf{n}$} & \multirow{2}{*}{$\begin{array}{c}\text { CL } \\
\text { n }\end{array}$} & \multirow{2}{*}{$\begin{array}{l}\text { Recovery } \\
\text { rate (\%) }\end{array}$} & \multicolumn{2}{|c|}{ Recovered embryos } & \multicolumn{5}{|c|}{ No. of oocytes/embryos* } \\
\hline & & & & $\mathbf{n}$ & mean \pm s.d. & Grade I & Grade II & Grade III & Grade IV & Unfert. \\
\hline Transcervical & 8 & 94 & 53.2 & 50 & $6.3 \pm 2.7$ & $21(42.0)$ & $20(40.0)$ & $3(6.0)$ & $3(6.0)$ & $3(6.0)$ \\
\hline Laparotomy & 5 & 84 & 36.9 & 31 & $6.2 \pm 4.1$ & $13(41.9)$ & $15(48.4)$ & $1(3.2)$ & $0(0.0)$ & $2(6.5)$ \\
\hline Total & 13 & 178 & 45.5 & 81 & $6.2 \pm 3.1$ & $34(42.0)$ & $35(43.2)$ & $4(5.0)$ & $3(3.7)$ & $5(6.1)$ \\
\hline
\end{tabular}

\section{Discussion}

The gonadotropic superovulation treatment used in the present study induced oestrus in a similar way to that cited by other researchers working on superovulation of goats. Baril et al. (1989) observed $89.5 \%$ of Saanen goats in oestrus when submitted to superovulation. In native goats of South Africa, Greyling et al. (2002) verified oestrus in $88.0 \%$ of the treated females. In the present study the interval between sponge removal and onset of oestrus was earlier than the results of Baril et al. (1989) and Baril \& Vallet (1990). The $\mathrm{pFSH}$ superovulation treatment is not followed by a compact synchronised oestrus. The onset of oestrus is in fact observed from 24 to 54 hours after sponge removal and about $10 \%$ of the does treated never expressed oestrus behaviour

Results concerning ovulation rate are in agreement with others that verified an ovulation rate ranging from 10 to 16 CL per donor (Ritar et al., 1988; Mc Natty et al., 1989; Baril \& Vallet, 1990). The early regression of the CL of the goat following the use of different hormonal superovulation treatments has been described by several authors (Armstrong et al., 1983; Moore, 1987; Pintado et al., 1998). However, this was not observed in the present study. 
Concerning the cervical penetrability, even with the application of cloprostenol, this study showed less cervical penetration than Suyadi et al. (2000) where 95 to 100\% cervical penetrability was observed in Boer goats. The results in the Saanen breed can possibly be explained by a greater occlusion of the cervical canal in this breed or by its lack of cervical dilatation response after injection of cloprostenol.

The embryo recovery rate obtained by the transcervical technique in Shiba and Boer goats varied from $89.5 \%$ (Nagashima et al., 1987) to 95\% (Suyadi et al., 2000), respectively. These recovery rates are greater than that obtained in the present experiment and those reported by Pereira et al. (1991) (39.6\%) who also worked with Saanen donors. The embryo recovery rate in goats subjected to laparotomy was less than the 70 to $80 \%$ reported by Baril et al. (1989) in Alpine and Saanen goats. The results from the present study may be due to the excessive manipulation of the cervix in attempts to recover embryos transcervically and the time factor.

Concerning the quality of the embryos, these findings are similar to those of other researchers using superovulatory treatments with pFSH on Alpine and Saanen goats in temperate climates (Baril et al., 1989; Vallet et al., 1991; Baril et al., 1995). Moreover, a great variation was observed in the embryo development between females collected at the same interval following the onset of oestrus. These differences in the development could increase the difficulty of the selection of embryos for transfer or freezing.

\section{Conclusion}

The transcervical approach to embryo collection was shown to be an alternative and simpler method in the practice of embryo transfer in Saanen goats. However, further studies should be conducted to improve both the cervix penetrability and the embryo recovery rate in goats of this breed.

\section{Acknowledgements}

The authors are grateful to the following Brazilian organs of financing: FUNCAP, CNPq and CAPES.

\section{References}

Armstrong, D.T., Pfitzner, A.P., Warnes, G.M. \& Seamark, R.F., 1983. Superovulation treatments and embryo transfer and Angora goats. J. Reprod. Fert. 70, 403-410.

Baril, G., Casamitjana, P., Perrin, J. \& Vallet, J.C., 1989. Embryo production, freezing and transfer in Angora, Alpine and Saanen goats. Zuchthygiene 24, 101-115.

Baril, G. \& Vallet, J.C., 1990. Time of ovulations in dairy goats induced to superovulate with porcine follicle stimulating hormone during and out of the breeding season. Theriogenology 34, 303-311.

Baril, G., Brebion, P. \& Chesné, P., 1995. Manual de formación práctica para el transplante de embriones en ovejas y cabras. FAO, Rome.

Chemineau, P., Procureur, R., Cognié, Y., Lefevre, P.C., Locatelli, A. \& Chupin, D., 1986. Production, freezing and transfer of embryos from a bluetongue-infected goat herd without bluetongue transmission. Theriogenology 25, 148 .

Flores-Foxworth, G., Mc Bride, B.M. \& Nuti, L.C., 1992. A comparison between laparoscopic and transcervical embryo collection and transfer in goats. Theriogenology 37, 213.

Goel, A.K., Tyagi, S. \& Agrawal, K.P., 1995. Nonsurgical collection of embryos from goats. Ind. J. Anim. Sci. 65, 293-296.

Greyling, J.P.C., Van der Nest, M., Schwalbach, L.M.J. \& Muller, T., 2002. Superovulation and embryo transfer in South African Boer and Indigenous feral goats. Small Rumin. Res. 43, 45-51.

IBGE, Anuário Estatístico do Brasil, 1998. IBGE, Rio de Janeiro.

Kraemer, D.C., 1989. Embryo collection and transfer in small ruminants. Theriogenology 31, 141-148.

McNatty, K.P., Hudson, N.L., Ball, K., Mason, A. \& Simmons, M.H., 1989. Superovulation and embryo recovery in goats treated with Ovagen and Folltropin. N. Z. Vet. J. 37, 27-29.

Nagashima, H., Matsui, K., Sawasaki, T. \& Kano, Y., 1987. Nonsurgical collection of embryos in Shiba goats. Exp. Anim. 36, 51-56.

Oldham, C.M. \& Lindsay, D.R., 1980. Laparoscopy in the ewe: A photographic record of the ovarian activity of ewes experiencing normal or abnormal oestrus cycles. Anim. Reprod. Sci. 3, 119-124.

Pereira, R.J.T.A., Lima, P.F., Silva, M.A.V., Wischral, A. \& Oliveira, M.A.L., 1991. Colheita de embriões caprinos por via transcervical. Rev. Bras. Reprod. Anim. 2, 314.

Pereira, R.J.T.A., Sohnrey, B. \& Holtz, W., 1998. Nonsurgical embryo collection in goats treated with prostaglandin F2 $\alpha$ and oxytocin. J. Anim. Sci. 76, 360-363. 
Pintado, B., Gutiérrez-Adán, A. \& Pérez Llano, B., 1998. Superovulatory response of Murciana goats to treatment based on PMSG/anti-PMSG or combined FSH/PMSG administration. Theriogenology 50, 357-364.

Ritar, A.J., Ball, P.D., O’May, P.J., Black, T.M., Jackson, R.B. \& Murray, N., 1988. Superovulation response and embryo recovery from Cashmere and Angora does after treatment with FSH. Aust. Soc. Reprod. Biol., Proc. $20^{\text {th }}$ Ann. Conf., Newcastle University, 29-31.

Suyadi, Sohnrey, B. \& Holtz, W., 2000. Transcervical embryo collection in Boer goats. Small Rumin. Res. $36,195-200$

Tamanini, C., Bono, G., Cairoli, F. \& Chiesa, F., 1985. Endocrine responses induced in anestrus goats by the administration of different hormones after a fluorogestone acetate treatment. Anim. Reprod. Sci. 9, 357364.

Tervit, H.R., Goold, P.G., McKenzie, R.D. \& Clarkson, D.J., 1983. Techniques and success of embryo transfers in Angora goats. N. Z. Vet. J. 31, 67-70.

Thibier, M. \& Guérin, B., 2000. Embryo transfer in small ruminants: the method of choice for health control in germ plasm exchanges. Livest. Prod. Sci. 62, 253-270.

Vallet, C.J., Casamitjana, P., Brebion, P. \& Perrin, J., 1991. Techniques de production, de conservation et de transfert d'embryons chez les petit ruminants. Rec. Méd. Vét. 31, 293-301. 